\title{
EFEKTIVITAS MODEL PEMBELAJARAN KOOPERATIF TIPE TEAMS GAMES TOURNAMENT (TGT) DAN TIPE RECIPROCAL PEER TUTORING (RPT) DITINJAU DARI MOTIVASI BERPRESTASI SISWA KELAS VIII SMP NEGERI DI KABUPATEN SUKOHARJO TAHUN AJARAN 2010/2011
}

\begin{abstract}
Nurtesti
Abstract

This research aims to determine: (1) which provides a better achievement between cooperative learning of TGT type and cooperative learning of RPT type, (2) which has a better achievement between students who have high achievement motivation, medium and low, (3) which provides a better learning mathematics achievement between learning with TGT type or RPT type on achievement motivation respectively high, medium or low, (4) which provides a better learning mathematics achievement among high, medium or low motivation achievement on learning with TGT type, and (5) which provides a better learning mathematics achievement among high, medium or low motivation achievement on learning with RPT type.

The population of this research was the eighth grade students of sukoharjo junior high school, second semester in the Academic Year 2010/2011. The sample size are 220 students taken from the SMP Negeri 1 Kartasura class VIII F and VIII F, SMP Negeri 2 Kartasura class VIII B and VIII C, and SMP Negeri 2 Gatak class VIII F and VIII G. Research sampling technique is stratified cluster random sampling. The instruments used to collect data is studying mathematics achievement tests and questionnaires student achievement motivation. Before the matehamtics achievement test and filling questionnaire of achievement motivation, we first conducted the instrument's trial. In trials of research mathematics achievement test, it was conducted a test on the level of difficulty items, the distinguishing and reliability. The achievement motivation questionnaire was conducted on internal consistency and reliability. The research of the preliminary test proved that those samples are normally distributed with the homogeneous variance and balanced. Than we conducted test of hypothesis using two-way analysis of variance (ANOVA) model with unequal cell frequencies to 5\% significance level. Prior to that, pre-requisite test: normality using the Lilliefors test and homogeneity of variances using the Bartlett test. The results of pre-requisite test are samples come from population with normal distribution and have homogeneity of variances

From the analysis, it was concluded that: (1) cooperative learning of TGT type give the same learning mathematics achievement with cooperative learning of RPT type, (2) students with high achievement motivation have to learn mathematics achievement better than students with medium and low achievement motivation, and students with medium and low achievement motivation has the same learning mathematics achievement, (3) learning model with the type of TGT and type of RPT result do not differ when given to students with high achievement motivation and students with low achievement motivation, but learning to type of TGT provide learning mathematics achievement is better than learning by students with the type of RPT on students with medium achievement motivation, (4) with the type of TGT, students with high, medium and low achievement motivation has the same learning mathematics achievement, (5) with the type of RPT, learning mathematics achievement students with high achievement motivation better than students with medium achievement motivation, while students with medium and low achievement motivation has the same learning mathematics achievement.
\end{abstract}

Keywords: Teams Games Tournament, Reciprocal Peer Tutoring, Achievement Motivation, Learning Mathematics Achievement

\section{PENDAHULUAN}

Salah satu upaya mengatasi kesulitan belajar matematika dan meningkatkan mutu pendidikan sekolah diantaranya adalah dengan menerapkan model pembelajaran 
yang inovatif. Model pembelajaran yang digunakan oleh guru dalam proses pembelajaran diusahakan bervariasi sehingga siswa terhindar dari rasa bosan dan tercipta suasana yang nyaman dan menyenangkan. Dalam proses pembelajaran terdapat berbagai macam model pembelajaran yang bertujuan agar proses pembelajaran dapat berjalan baik. Hal ini juga bertujuan untuk menciptakan proses pembelajaran yang aktif serta memungkinkan timbulnya sikap keterkaitan siswa untuk mengikuti kegiatan pembelajaran secara menyeluruh. Pembelajaran yang efektif tersebut harus diimbangi dengan kemampuan guru dalam menguasai model pembelajaran dan materi yang akan diajarkan. Seiring diberlakukannya Kurikulum Tingkat Satuan Pendidikan (KTSP) diharapkan guru dapat meningkatkan prestasi siswa khususnya pada pelajaran matematika dengan berkreasi dan berinovasi menggunakan berbagai macam model pembelajaran yang berkembang saat ini.

Proses pembelajaran yang baik adalah yang dapat menciptakan proses pembelajaran yang efektif dengan adanya komunikasi dua arah antara guru dengan siswa yang tidak hanya menekankan pada apa yang dipelajari tetapi menekankan bagaimana siswa harus belajar. Salah satu pandangan tentang pembelajaran adalah pandangan konstruktivisme. Pandangan ini menuntut peran aktif siswa dalam membangun pemahaman dan menguasai konsep. Salah satu model pembelajaran yang berlandaskan pada pandangan konstruktivisme adalah model pembelajaran kooperatif. Pembelajaran kooperatif menyediakan kesempatan pada siswa untuk menggembangkan kemampuan interaksi dalam kelompok dan bekerja dengan orang lain, dimana kemampuan ini sanngat dibutuhkan di dunia sekarang (Wyk, 2011: 183). Dua tipe pembelajaran koopertif yang menarik adalah tipe Times Games Tournament (TGT) dan Reciprocal Peer Tutoring (RPT).

Model pembelajaran kooperatif tipe TGT merupakan tipe pembelajaran dengan mengelompokkan siswa ke dalam tim dengan kemampuan heterogen untuk berkompetisi dalam suatu permainan, dengan tujuan menciptakan suasana kelas yang efektif sehingga siswa secara aktif terlibat dalam proses pengajaran dan termotivasi untuk mengupayakan keberhasilan tim. Tipe pembelajaran ini mudah diakses dan diaplikasikan pada seluruh tingkatan dan mata pelajaran di sekolah (Wyk, 2011: 186).

Model pembelajaran kooperatif tipe RPT adalah bukti dari pembelajaran kooperatif, yang telah ditemukan sebagai teknik yang efektif dalam meningkatkan prestasi akademik siswa (Sherman dan Slavin, dalam Obiunu, 2008: 236). Dalam setiap eksperimen Fantuzzo, RPT telah diimplementasikan dalam cara berikut ini: 1) siswa dipasangkan dengan seorang rekan, 2) setiap siswa mengembangkan seri 
pertanyaan sesuai topik, dan 3) siswa membuat soal-soal mereka pada rekan, sebelum ujian di kelas keseluruhan, kemudian memberikan pengajaran pada rekan mereka yang bermasalah pada topik ini (Rittschof and Griffin, 2001: 316).

Dari implementasi RPT di atas, posisi siswa menjadi tutor (pengajar pribadi teman sebaya) ketika siswa membuat pertanyaanpertanyaan untuk rekannya dan memberikan penjelasan pada rekannya yang tidak dapat menjawab item pertanyaan darinya dan posisi tutee (siswa pribadi) ketika siswa diberi pertanyaan dan penjelasan oleh rekannya. Menurut Griffin and Griffin (dalam Choudhury, 2002: 137) pada RPT, fungsi siswa sama yaitu sebagai tutor dan tutee. Ini memungkinkan siswa untuk memperoleh kedua keuntungan dari persiapan dan instruksi yang digunakan tutor, dan dari instruksi yang diterima oleh tutee. Ditambahkan oleh Slavin (2011: 242) bahwa tutor dan tutee keduanya dapat diuntungkan: tutee dapat memelajari konsep akademis dan tutor memeroleh penerimaan dan pemahaman yang lebih baik terhadap siswa yang mempunyai ketidakmapuan.

Motivasi berprestasi siswa merupakan salah satu faktor penting dalam kegiatan pembelajaran matematika. Rao (2003:13) menjelaskan motivasi berprestasi adalah harapan untuk menemukan kepuasan dalam menguasai tantangan dan perbuatan yang sulit, motivasi untuk menampilkan tugastugas khusus untuk memiliki standar pesaing unggul dengan hasil yang dapat dinilai. Dengan motivasi berprestasi siswa dapat melakukan sesuatu sebaik-baiknya dan tekun dalam menyelesaikan permasalahan matematika hingga mencapai standar tertinggi.

\section{METODOLOGI PENELITIAN}

Dalam penelitian ini, peneliti menggunakan penelitian eksperimental semu (quasi-experimental research), sebab peneliti tidak mungkin untuk mengontrol semua variabel yang relevan (Budiyono, 2003:82). Pada penelitian ini terdapat dua variabel bebas yaitu model pembelajaran dan gaya belajar. Sedangkan variabel terikatnya adalah prestasi belajar matematika.

Populasi dalam penelitian ini adalah seluruh siswa kelas VIII SMP Negeri seKabupaten Sukoharjo semester genap tahun pelajaran 2010/2011. Teknik pengambilan sampel yang digunakan dalam penelitian ini adalah stratified cluster random sampling. Pada awal sebelum memulai perlakuan terlebih dahulu mengecek keadaan kemampuan awal dari sampel yang akan dikenai perlakuan, baik dari kelompok eksperimen I maupun kelompok eksperimen II. Hal ini bertujuan untuk mengetahui apakah dua kelompok tersebut dalam keadaan seimbang. Data yang digunakan untuk menguji keseimbangan adalah nilai raport matematika semester gasal tahun pelajaran 2010/2011.

Pengambilan data dengan menggunakan metode dokumentasi, angket dan tes. Metode dokumentasi digunakan 
untuk mengumpulkan data tentang daftar nama dan nilai raport matematika semester gasal tahun ajaran 2010/2011. Angket digunakan untuk mengambil data motivasi berprestasi matematika siswa, dan tes digunakan untuk mengambil data prestasi belajar matematika siswa pada materi bangun ruang sisi datar: kubus, balok, prisma, dan limas.

Penelitian ini menggunakan rancangan faktorial 2 x 3, dengan maksud untuk mengetahui pengaruh dua variabel bebas terhadap variabel terikat.

Tabel 3.4.Rancangan Penelitian

\begin{tabular}{|l|l|l|l|}
\hline Mot.B & $\begin{array}{l}\text { Tinggi } \\
\left(\boldsymbol{b}_{\mathbf{1}}\right)\end{array}$ & $\begin{array}{l}\text { Sedang } \\
\left(\boldsymbol{b}_{\mathbf{2}}\right)\end{array}$ & $\begin{array}{l}\text { Rendah } \\
\left(\boldsymbol{b}_{\mathbf{3}}\right)\end{array}$ \\
\hline TGodel & $\left.\mathrm{ab}_{11}\right)$ & $\mathrm{ab}_{12}$ & $\mathrm{ab}_{13}$ \\
\hline $\operatorname{RPT}\left(a_{2}\right)$ & $\mathrm{ab}_{21}$ & $\mathrm{ab}_{22}$ & $\mathrm{ab}_{23}$ \\
\hline
\end{tabular}

Uji hipotesis yang dilakukan adalah menggunakan anava dua jalan dengan sel tak sama. Untuk mengetahui pengaruh efek antar baris dan antar kolom, maka dilakukan uji lanjut anava denga metode Schefee.

\section{HASIL PENELITIAN}

Berdasarkan hasil perhitungan uji keseimbangan diperoleh $t_{\text {hitung }}=-0,167$ dan $t_{\text {tabel }}=1,96$. Dengan demikian $H_{0}$ diterima. Berdasarkan keputusan uji tersebut, maka dapat disimpulkan bahwa kedua kelompok dalam keadaan seimbang atau memiliki kemampuan awal sama.

Tes prestasi belajar matematika pada materi bangun ruang sisi datar diuji cobakan sebanyak 35 butir soal. Berdasarkan penilaian yang dilakukan oleh dua validator diperoleh hasil bahwa semua butir tes memenuhi semua aspek dan dapat digunakan untuk mengambil data penelitian. Berdasarkan perhitungan tingkat kesukaran soal tes, menunjukkan bahwa ada 3 butir soal yang tidak memadai, karena indeks tingkat kesukarannya kurang dari 0,3 (butir 3) dan lebih dari 0,7 (butir 6 dan 31). Sedangkan untuk daya pembeda butir soal, menunjukkan bahwa ada ada 3 item yang menunjukkan kriteria tidak baik, karena daya pembeda soalnya kurang dari 0,3 (butir 3, 6 dan 31). Dari perhitungan diatas dapat diperoleh 32 butir soal yang memadai dan dipilih 32 soal yang akan digunakan untuk mengambil data yaitu butir soal nomor $1,2,5,7,8,9,10,11,12,13,14$, $15,16,17,18,19,20,21,22,23,25,26$, $27,28,29,30,32,33,34$, dan 35. Butir soal nomor 24 tidak digunakan karena indikator yang mencakup butir tersebut telah cukup terwakili oleh butir soal nomor 16, 19, dan 33, sedangkan butir soal nomor 4 tidak digunakan karena indikator yang mencakup butir tersebut telah cukup terwakili oleh butir soal nomor 2, 9 dan 18. Dengan menggunakan rumus K-R 20 dari KuderRichardson, diperoleh hasil perhitungan indeks reliabilitas tes prestasi belajar matematika pada materi pokok aljabar dan aritmetika sosial sebesar $r_{11}=0,849>0,7$, sehingga dapat disimpulkan bahwa tes reliabel.

Angket motivasi berprestasi matematika siswa terdiri dari 40 butir pernyataan. Berdasarkan penilaian yang 
dilakukan oleh dua validator diperoleh hasil bahwa semua butir tes memenuhi semua aspek dan dapat digunakan untuk mengambil data penelitian. Hasil uji coba angket motivasi berprestasi dengan perhitungan rumus korelasi product momen, diperoleh 6 butir angket mempunyai indeks konsistensi $<0,3$, yaitu butir angket nomor: 1, 7, 11, 14, 18, dan 39 sehingga butir angket tersebut tidak digunakan untuk penelitian lebih lanjut. Kemudian dipilih 15 butir yang akan digunakan untuk mengambil data yaitu butir: 1, 2, 3, 4, 5, $6,7,8,9,10,13,14,16,18,19$. Uji konsistensi angket gaya belajar auditorial menunjukkan 3 butir gugur yaitu butir 2, 9 , dan 11. Kemudian dipilih 15 butir yang akan digunakan untuk mengambil data yaitu butir: 1, 3, 4, 5, 6, 7, 8, 12, 14, 15, 16, 17, 18, 19, 20. Sedangkan uji konsistensi angket gaya belajar kinestetik menunjukkan 3 butir gugur yaitu butir 12, 17, dan 19 . Kemudian dipilih 15 butir yang akan digunakan untuk mengambil data yaitu butir: $1,2,3,4,5,6,7,8,9,11,13,14,16$, 18, 20. Dengan menggunakan teknik Alpha dari Cronbach dengan menghitung koefisien reliabilitas diperoleh untuk gaya belajar visual $r_{11}=0,7695$, auditorial $r_{11}$ $=0,7592$, dan kinestetik $r_{11}=0,7737$.

Hasil uji normalitas skor prestasi belajar matematika siswa untuk kelompok eksprimen I dengan uji Liliefors diperoleh hasil $\mathrm{L}_{\mathrm{obs}}=0,0741$ dan untuk kelompok eksperimen II $\mathrm{L}_{\mathrm{obs}}=0,0613$. Untuk kelompok siswa dengan gaya belajar visual
$\mathrm{L}_{\mathrm{obs}}=0,0722$, auditorial $\mathrm{L}_{\mathrm{obs}}=0,0823$, dan kinestetik $\mathrm{L}_{\mathrm{obs}}=0,0985$. Dengan mengambil taraf signikansi $5 \%$, dapat disimpulkan bahwa sampel diambil dari populasi yang berdistribusi normal.

Dalam penelitian ini ada dua kali uji homogenitas variansi, yaitu antar baris (uji homogenitas prestasi belajar siswa ditinjau dari metode pembelajaran) dan antar kolom (uji homogenitas prestasi belajar siswa ditinjau dari motivasi berprestasi siswa), hasilnya adalah untuk tipe pembelajaran diperoleh $\chi_{\mathrm{obs}}^{2}=1,804$ dan untuk motivasi berprestasi diperoleh $\chi_{\text {tabel }}^{2}=3,841$. dengan demikian dapat disimpulkan bahwa sampel berasal dari populasi yang homogen.

Hasil perhitungan analisis variansi dua jalan (2x3) sel tak sama dan uji komparasi ganda dengan taraf signifikansi $\square=0,05$ menunjukkan bahwa (1) Prestasi belajar siswa yang dihasilkan oleh tipe TGT tidak berbeda dengan prestasi belajar siswa yang dihasilkan tipe RPT, (2) Siswa dengan motivasi berprestasi tinggi, sedang dan rendah mempunyai prestasi belajar matematika yang berbeda. untuk $\mathrm{H}_{01}$ diperoleh $\mathrm{F}_{\mathrm{obs}}=6,1703>2 . \mathrm{F}_{(0,05 ; 2 ; 214)}=6,00$ sehingga $\mathrm{H}_{01}$ ditolak. Ini berarti motivasi berprestasi tinggi dan motivasi berprestasi sedang memberikan prestasi belajar matematika yang berbeda. Dengan melihat rerata marginal, motivasi berprestasi tinggi memiliki rerata 74,3071 sedangkan motivasi berprestasi sedang memiliki rerata 68,5128 sehingga dapat disimpulkan 
motivasi berprestasi tinggi memberikan prestasi yang lebih baik daripada motivasi berprestasi sedang. Untuk $\mathrm{H}_{02}$ diperoleh $\mathrm{F}_{\text {obs }}=9,0431>2 \cdot \mathrm{F}_{(0,05 ; 2 ; 214)}=6,00$ sehingga $\mathrm{H}_{02}$ ditolak. Ini berarti motivasi berprestasi tinggi dan motivasi berprestasi rendah memberikan prestasi belajar yang berbeda. Dengan melihat rerata marginal, motivasi berprestasi tinggi memiliki rerata 74,3071 sedangkan motivasi berprestasi rendah memiliki rerata 67,3232 sehingga dapat disimpulkan bahwa motivasi berprestasi tinggi memberikan prestasi belajar yang lebih baik daripada motivasi berprestasi rendah. Sedangkan untuk $\mathrm{H}_{03}$ diperoleh $\mathrm{F}_{\mathrm{obs}}=0,2267<2 . \mathrm{F}_{(0,05 ; 2 ; 214)}=$ 6,00 sehingga $\mathrm{H}_{03}$ diterima. Ini berarti motivasi berprestasi sedang dan motivasi berprestasi rendah memberikan prestasi belajar matematika yang sama, (3) Berdasarkan hasil uji coba komparasi rerata anta sel pada baris yang sama untuk tipe TGT, untuk $\mathrm{H}_{01}$ diperoleh $\mathrm{F}_{\mathrm{obs}}=0,4085<5$ . $\mathrm{F}_{(0,05 ; 5 ; 214)}=11,05$ sehingga $\mathrm{H}_{01}$ diterima. Ini berarti motivasi berprestasi tinggi dan motivasi berprestasi sedang memberikan prestasi belajar matematika yang sama. Untuk $\mathrm{H}_{02}$ diperoleh $\mathrm{F}_{\mathrm{obs}}=8,0259<5$. $\mathrm{F}_{(0,05 ; 5 ; 214)}=11,05$ sehingga $\mathrm{H}_{02}$ diterima. Ini berarti motivasi berprestasi sedang dan motivasi berprestasi rendah memberikan prestasi belajar matematika yang sama. Untuk $\mathrm{H}_{03}$ diperoleh $\mathrm{F}_{\mathrm{obs}}=5,4576<5$. $\mathrm{F}_{(0,05 ; 5 ; 214)}=11,05$ sehingga $\mathrm{H}_{03}$ diterima. Ini berarti motivasi berprestasi tinggi dan motivasi berprestasi rendah memberikan prestasi belajar matematika yang sama, (4) Berdasarkan hasil uji coba komparasi rerata anta sel pada baris yang sama untuk tipe RPT, untuk $\mathrm{H}_{04}$ diperoleh $\mathrm{F}_{\text {obs }}=21,2327>$ 5 . $\mathrm{F}_{(0,05 ; 5 ; 214)}=11,05$ sehingga $\mathrm{H}_{04}$ ditolak. Ini berarti motivasi berprestasi tinggi dan motivasi berprestasi sedang memberikan prestasi belajar matematika yang berbeda. Dengan melihat rerata, motivasi berprestasi tinggi memiliki rerata 75,7333 sedangkan motivasi berprestasi sedang memiliki rerata 60 sehingga dapat disimpulkan motivasi berprestasi tinggi memberikan prestasi belajar matematika yang lebih baik daripada motivasi berprestasi sedang. Untuk $\mathrm{H}_{05}$ diperoleh $\mathrm{F}_{\mathrm{obs}}=6,8690<5$. $\mathrm{F}_{(0,05 ; 5 ; 214)}=11,05$ sehingga $\mathrm{H}_{05}$ diterima. Ini berarti motivasi berprestasi sedang dan motivasi berprestasi rendah memberikan prestasi belajar matematika yang sama. Sedangkan untuk $\mathrm{H}_{06}$ diperoleh $\mathrm{F}_{\mathrm{obs}}=$ $3,3701<5 . \mathrm{F}_{(0,05 ; 5 ; 214)}=11,05$ sehingga $\mathrm{H}_{06}$ diterima. Ini berarti motivasi berprestasi tinggi dan motivasi berprestasi rendah memberikan prestasi belajar matematika yang sama.

\section{KESIMPULAN}

1. Pembelajaran dengan tipe TGT memberikan prestasi belajar matematika yang sama dengan menggunakan tipe RPT.

2. Siswa dengan motivasi berprestasi tinggi mempunyai prestasi belajar matematika yang lebih baik daripada siswa dengan motivasi berprestasi 
sedang maupun rendah. Di sisi lain, siswa dengan motivasi berprestasi sedang mempunyai prestasi belajar matematika yang sama dengan siswa dengan motivasi berprestasi rendah.

3. Pembelajaran dengan tipe TGT memberikan prestasi belajar matematika yang sama dengan menggunakan tipe RPT pada siswa dengan motivasi berprestasi tinggi dan siswa dengan motivasi berprestasi rendah, pembelajaran dengan tipe TGT memberikan prestasi belajar matematika yang lebih baik daripada dengan menggunakan tipe RPT pada siswa dengan motivasi berprestasi sedang.

4. Pada pembelajaran dengan menggunakan tipe TGT, siswa dengan motivasi berprestasi tinggi mempunyai prestasi belajar matematika yang sama dengan siswa dengan motivasi berprestasi sedang serta mempunyai prestasi belajar yang sama dengan siswa dengan motivasi berprestasi rendah.

5. Pada pembelajaran dengan menggunakan tipe RPT, siswa dengan motivasi berprestasi tinggi mempunyai prestasi belajar yang lebih baik daripada siswa dengan motivasi berprestasi sedang, siswa dengan motivasi berprestasi sedang mempunyai prestasi belajar matematika yang sama dengan siswa dengan motivasi berprestasi rendah, siswa dengan motivasi berprestasi tinggi mempunyai prestasi belajar matematika sama dengan siswa dengan motivasi berprestasi rendah.

\section{DAFTAR PUSTAKA}

Alex Sobur. 2003. Psikologi Umum. Bandung: Pustaka Setia.

Anas Sudijono. 2009. Pengantar Evaluasi Pendidikan. Jakarta: PT Rajagrafindo Persada.

Apriyanto Hadi Nugroho. 2011. Eksperimentasi Model Pembelajaran Kooperatif Tipe Teams Games Tournament (TGT) dan Tipe Think Pair Share (TPS) ditinjau dari Motivasi Berprestasi Siswa. Tesis. Surakarta: Universitas Sebelas Maret.

Atrie Bintan Lestari dan Hendro Prabowo. 2008. Perbedaan Motivasi Berprestasi Ditinjau dari Orientasi Pusat Kendali pada Mahasiswa. Universitas Gunadarma.

Badan Standar Nasional Pendidikan. 2011. Prosedur Operasi Standar Ujian Nasional. Jakarta: BSNP

Budiyono . 2003. Metodologi Penelitian Pendidikan. Surakarta : UNS Press. 2009. Statistika Untuk Penelitian Edisi Ke-2. Surakarta : UNS Press.

Choudhury, I. 2002. "Use of Reciprocal Peer Tutoring Technique in an Environmental Control Systems Course at an Undergraduate Level". Journal of Construction Education. 7 (3), pp. 137-142. http: //proquest.umi.com/pqdweb?index24. Diakses tanggal 27 Januari 2011.

Crain, William. 2007. Teori Perkembangan: Konsep dan Aplikasi. Yogyakarta: Pustaka Pelajar. 
Depdiknas. 2003. Undang-Undang Sistem Pendidikan Nasional. Jakarta : Depdiknas.

Depdiknas. 2006. Peraturan Mendiknas No. 22 tentang Standar Isi. Jakarta : Depdiknas.

Depdiknas. 2007. Peraturan Mendiknas No. 20 tentang Standar Penilaian Pendidikan. Jakarta: Depdiknas.

Dita Yuzianah. 2011. Efektivitas Pembelajaran Kooperatif Tipe Numbered Heads Together (NHT) dan Student Team Achievement Division (STAD) pada Prestasi Belajar Matematika Ditinjau dari Motivasi Berprestasi. Tesis. Surakarta: Universitas Sebelas Maret.

Dufrene, B.A., Noell, G.H., Gilbertson, D.N., and Duhon, G.J. 2005. "Monitoring Implementation of Reciprocal Peer Tutoring: Identifying and Intervening With Students Who Do Not Maintain Accurate Implementation". School Psychology Review. 2005. 34 (1). pp. 74-86. http://proquest.umi.com/ pqdweb. Diakses tanggal 27 Januari 2011.

Eveline Siregar dan Hartini Nara. 2010. Teori Belajar dan Pembelajaran. Bogor: Ghalia Indonesia.

George, P.G. 1994. "The Efectiveness of Cooperative Learning Strategies in Multicultural University Classrooms". Journal on Excellence in College Teaching. 5 (1). pp. 21-30. http://proquest.umi.com/pqdweb?index =15. Diakses tanggal 27 Januari 2011.

Isjoni. 2010. Cooperative Learning: Mengembangkan Kemampuan Belajar Kelompok. Bandung: Alfabeta

Ke, F. and Grabowski, B. 2007. "Gameplaying for maths learning: cooperative or not?". British Journal of Educational Technology. 38 (2). pp. 249-259. http://proquest.umi.com/pqdweb.

Diakses tanggal 27 Januari 2011.

Liu, E.Z.F and Cheng, S.S. 2007. "The Student Satisfaction and Effect of Group Discussion on Networked Cooperatif Learning with The Portopolio Assesment System". International Journal Education and Information Technologies. 1(3). pp. 161-166.

http://proquest.umi.com/pqdweb? index $=2$. Diakses tanggal 27 Januari 2011.

Malara, N.A. 2003. "Dialectics Between Theory and Practice: Theoretical Issues and Aspects of Practice From an Early Algebra Project". Journal International Group For The Psychology of Mathematics Education. 1(2). $\quad$ pp. 33-49. http://proquest.umi.com/pqdweb?index =9. Diakses tanggal 27 Januari 2011.

Mickelson, W.T., Yetter, G., Lemberger, M., Hovater, S., and Ayers, R. 2003. Reciprocal Peer Tutoring: An Embedded Assessment Technique to Improve Student Learning and Achievement. Lincoln: Educational Psychology Department. http://proquest.umi.com/pqdweb. Diakses tanggal 27 Januari 2011.

Moore. L.L., Grabsch, G.K., and Rotter, C. 2010. "Using Achievement Motivation Theory to Explain Student Participation in a Residential Leadership Learning Community". Journal of Leadership Education. 9 (2). pp. 22-34. http://proquest.umi.com/pqdweb?index =34. Diakses tanggal 27 Januari 2011.

Nuzulia Mufida. 2010. Eksperimentasi Model pembelajaran Kooperatif Tipe Teams Games Tournament (TGT) Pada Pokok Bahasan Bangun Ruang Sisi Lengkung ditinjau dari Gaya Belajar Siswa Kelas IX MTS Negeri Se-Kabupaten Klaten Tahun Pelajaran 2009/2010. Tesis. Surakarta: Universitas Sebelas Maret. 
Obiunu, J.J. 2008. "The Effects of Reciprocal Peer Tutoring on The Enhancement of Career Decision Making Process Among Secondary School Adolescents". Academic Journals. 3 (7), pp. 236-241. http: //proquest.umi.com/pqdweb?. Diakses tanggal 27 Januari 2011

Rao, M.S. 2003. Achievement Motivation and Achievement in Mathematics. New Delhi: Discoveri Publishing House.

Reber, A.S. and Reber, E.S. 2010. Kamus Psikologi.Yogyakarta: Pustaka Pelajar.

Rittschof, K.A. and Griffin B.W. 2001. "Reciprocal Peer Tutoring: ReExamining The Value of a CoOperative Learning Technique to College Students and Instructors". Educational Psychology, 21 (3), pp. 313-331. http: //proquest.umi.com. Diakses tanggal 27 Januari 2011

Rolka, K., Rösken, B., and Liljedahl, P. 2006. "Challenging The Mathematical Beliefs of Preservice Elementary School Teachers". Prague: PME30. Vol 4. pp. 441-448. http://www.lettredelapreuve.it/OldPreu ve/ Newsletter. Diakses tanggal 27 Januari 2011

Santrock, J.W. 2007. Psikologi Pendidikan edisi kedua. Jakarta: Kencana

Sistem Informasi Hasil Ujian Nasional Tahun 2009, software
Sistem Informasi Hasil Ujian Nasional Tahun 2010, software

Slavin, R.E. 2005. Cooperative Learning; Teori, Riset dan Praktek. Bandung: Nusa Media.

Slavin, R.E. 2011. Psikologi Pendidikan Teori dan Praktek Jilid 2. Jakarta: PT. Indeks

Sugiyono. 2009. Statistika untuk Penelitian. Bandung : Alfabeta

Trianto. 2010. Mendesain Model Pembelajran Inovatif-Progresif; Landasan dan Implementasinya pada Kurikulum Tingkat Satuan pendidikan (KTSP). Jakarta: Prenada Medi Group.

Winkel, W.S. 2009. Psikologi Pengajaran. Yogyakarta: Media Abadi.

Wyk, M.M. 2011. "Effect of TeamsGames-Tournaments on Achivement, Retention, and Attitudes of Economics Education Students". Journal Social Sciense. 26(3). pp. 183-193. http://proquest.umi.com/pqdweb?. Diakses tanggal 27 Januari 2011.

Yevdokimov, O. 2004. "About a Cinstructivist Approach for Stimulating Students Thinking to Prodece Conjectures and Their Proving in Active Learning of Geometry". CERME 4 Proceeding, pp. 469-478. http://www. lettredelapreuve.it/OldPreuve/Newslett er/05Automne/CERME4Yevdokimov. Diakses tanggal 27 Januari 2011. 